\title{
Case Report: Anesthesia in Patients with Asphyxiating Thoracic Dystrophy: Jeune Syndrome
}

\author{
Deise Saletti ${ }^{1}$, Thiago Ramos Grigio ${ }^{2}$, Deoclecio Tonelli, TSA ${ }^{3}$, Onésimo Duarte Ribeiro Júnior ${ }^{4}$, \\ Fabríccio Marini ${ }^{5}$
}

Summary: Saletti D, Grigio TR, Tonelli D, Ribeiro Júnior OD, Marini F - Case Report: Anesthesia in Patients with Asphyxiating Thoracic Dystrophy: Jeune Syndrome.

Background and objectives: Jeune Syndrome or Asphyxiating Thoracic Dystrophy is a recessive autosomal disease. This syndrome is characterized by a bone dysplasia with varied abnormalities: thoracic, pancreatic, cardiac, hepatic, renal and retinal. Patients' age when the clinical condition is experienced correlates with the disease severity. These patients experience polychondrodystrophy with large, short, horizontal ribs and irregular costochondral junctions resulting in a rigid and reduced thoracic cage with varied respiratory injury level.

Case Report: Male patient, 4 months-old, 7 kg, suffering with Asphyxiating Thoracic Dystrophy, intubated and presented with reduced thoracic cage. Echocardiogram: mild pulmonary hypertension. Chest tomography: pulmonary hypoplasia. Patient submitted to bilateral thoracoplasty and thoracotomy with general anesthesia. Anesthesia maintenance: sufentanil e sevoflurane continuous infusion. Ventilation parameters: pressurecycled mechanical ventilation. Thorax opening provided improvement of the ventilation parameters, but after thoracic prosthesis placement, ventilation was limited. Reduction of the thoracic prosthesis was considered with consequent improvement of ventilation.

Conclusions: Diagnosis of all present abnormalities is essential for the correct anesthetic management. Observation was necessary to adequate pre- and post-thoracotomy/thoracoplasty ventilation and to maintain patient hemodynamically stable. Pressure-cycled mechanical ventilation is the most adequate type of ventilation to overcome the mechanical barrier. In the intraoperative setting, the ideal is to maintain the inspiratory pressure peak as low as possible to minimize the risk of barotrauma, venous return impairment and reduced cardiac output.

Keywords: Anesthesia, General; Genetic Diseases, Inborn/Jeune Syndrome; Respiration, Artificial; Thoracic Surgery.

C2012 Elsevier Editora Ltda. All rights reserved.

\section{INTRODUCTION}

Jeune Syndrome (JS) or Asphyxiating Thoracic Dystrophy is a rare recessive autosomal disease located in the chromosome $15 q 13^{1,2}$. It occurs at a frequency of $1: 100,000$ to $1: 130,000$ newborns alive in the United States ${ }^{1}$. This syndrome is characterized by a bone dysplasia with varied abnormalities - thoracic, pancreatic, cardiac, hepatic, renal and retinal. The age when the clinical condition is experienced is considered to be correlated with the disease severity ${ }^{2-7}$. Showing a great variety in the clinical condition, cases may be leveled as: lethal,

Received from $A B C$ Foundation and Medical School at ABC, Brazil.

1. MD; Collaborator, CET at Medical School at ABC (FMABC)

2. $M D$; Specialization in Anesthesiology, CET-FMABC

3. Assistant Professor, Anesthesiology, FMABC; Coordinator, CET-FMABC

4. Health Sciences Master Degree, FMABC; Assistant Professor, Anesthesiology, FMABC;

Professor, Antalgic Therapy, Nursing School at ABC Foundation

5. Anesthesiologist

Submitted on December 29, 2010.

Approved on August 3, 2011.

Correspondence to:

Thiago Ramos Grigio, MD

Rua Pedro Pomponazzi, 230, apto 151

Vila Mariana

04115000 - São Paulo, SP, Brazil

E-mail: tr.grigio@uol.com.br sever, moderate and underlying forms ${ }^{2,3}$. Most of the deaths occur during the perinatal period as the short thorax and hypoplastic lungs lead to asphyxia $2,6,7$.

In the moderate forms, the child experiences repeated pneumonias with progressive respiratory failure in the first year of life ${ }^{7}$. Typically, these patients are mechanical ventilation dependents 7,8 . Some lately diagnosed patients may experience adequate ventilation when resting, and improve respiratory capacity along the years ${ }^{7}$.

Pulmonary function ranges from normal and may reach pulmonary hypertension due to pulmonary hypoplasia 1,7 . Occasional cardiac involvement results from cardiac failure secondary to an increased pulmonary vascular resistance, a thoracic constriction, an alveolar hypoplasia, and a primary myocardial disease ${ }^{1}$. There may be liver impairment with prolonged neonatal jaundice, hepatic polycystic disease, bile duct hyperplasia and congenital hepatic cirrhosis ${ }^{2-4}$. Additionally, renal failure is caused by diffuse interstitial fibrosis with lymphoblastic infiltration and tubular alterations (intercalated dilatation and atrophy) ${ }^{1,2,4}$. Polyuria, polydipsia and hypertension may occur in the second or third year of life, while renal failure develops in childhood and adolescence ${ }^{1,9}$. Patients may experience intestine malabsorption, degeneration of the retina, polydactyly and dental and pelvic abnormalities ${ }^{2}$.

These patients experience polychondrodystrophy with large, short, horizontal ribs and irregular costochondral junctions resulting in a rigid thoracic cage $1,2,5-7,9,10$. The thoracic 


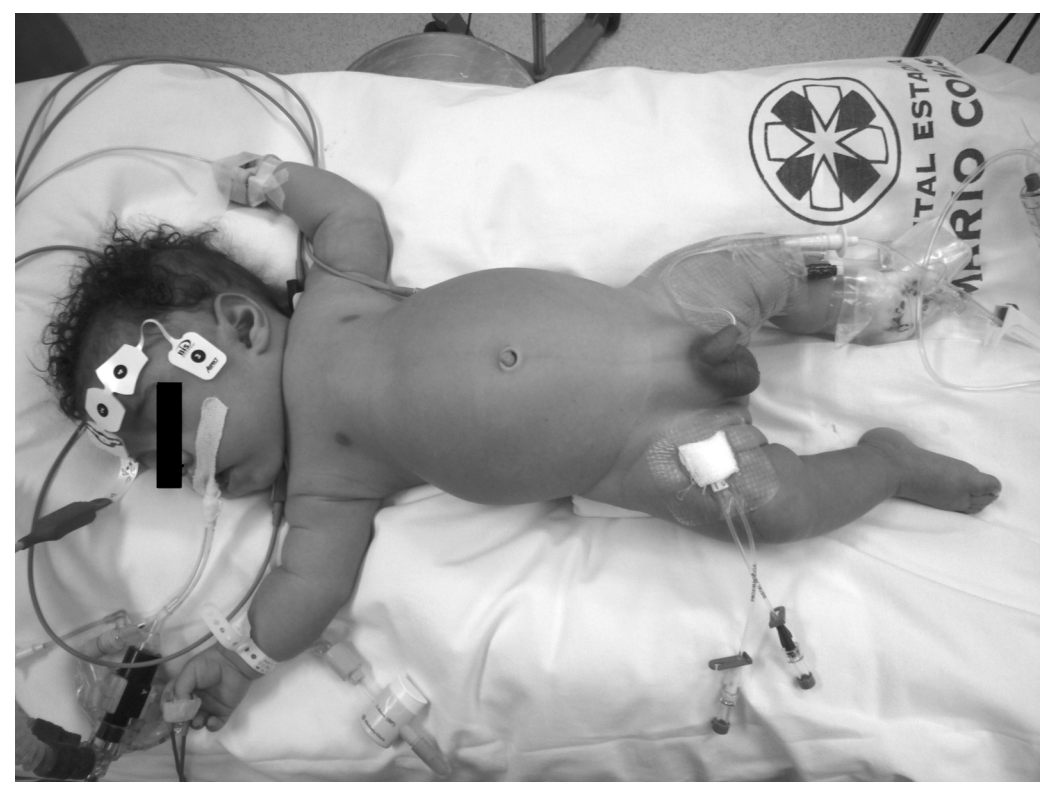

Figure 1 -Thorax/Abdomen Disproportion.

cage is extremely reduced and causes pulmonary restriction ${ }^{1,7}$. All patients experience reduced thorax, though the respiratory injury level may vary from insignificant to death ${ }^{1-3,7}$.

The purpose of this article is to report an anesthesia case in a patient with Jeune Syndrome reported in the University Anesthesiology Service at the Hospital Estadual Mário Covas - Medical School of ABC.

\section{Case Report}

Male patient, 4 months-old, $7 \mathrm{~kg}$, ASA III, with Jeune Syndrome, presenting with pulmonary and bone alterations. Among the pulmonary alterations were observed pulmonary hypoplasia and rigid thoracic cage.

In the physical examination, patient was hydrated, with normal skin color, intubated with volume-cycled mechanical ventilation, with reduced thoracic cage and short limbs. No alterations in the cardiac or pulmonary auscultation (Figure 1).

Laboratory Tests: Hemoglobin 10.9 mg.dL-1 , Hematocrit $30.9 \%$, leukocytes $11,500 . \mathrm{mm}^{-3}$ without deviation, platelets $268,000 . \mathrm{mm}^{-3}$, coagulation which changes, sodium $135 \mathrm{mg} \cdot \mathrm{dL}^{-1}$, potassium $4.4 \mathrm{mg} \cdot \mathrm{dL}^{-1}$, creatinine $0.9 \mathrm{mg} \cdot \mathrm{dL}^{-1}$, total calcium $9.2 \mathrm{mg} \cdot \mathrm{dL}^{-1}$, ionized calcium $1.34 \mathrm{mg} \cdot \mathrm{dL}^{-1}$, magnesium 1.7 mg.dL-1, gasometry: $\mathrm{pH}$ 7.510, $\mathrm{PaO}_{2}$ $218.2 \mathrm{~mm} \mathrm{Hg}, \mathrm{PaCO}_{2} 32.8 \mathrm{~mm} \mathrm{Hg}, \mathrm{HCO}_{3} 25.6$ mmol.L-1, BE $3.1 \mathrm{mmol} . \mathrm{L}^{-1}, \mathrm{O}_{2}$ saturation $99.2 \%$.

Echocardiogram: Normal ejection fraction, normal cardiac valves, mild pulmonary hypertension.

Thorax radiography: Reduced thoracic cage (Figure 2). Chest tomography: Pulmonary hypoplasia, short and rectified ribs.
Monitoring: Cardioscopy, pulse oximetry, expiratory capnography, invasive blood pressure, bispectral index (BIS), thermal blanket and indwelling catheters. Patient was submitted to bilateral thoracoplasty for subsequent thoracotomy with general anesthesia. Previous peripheral venous access established in upper right limb (Jelco® 24). In the

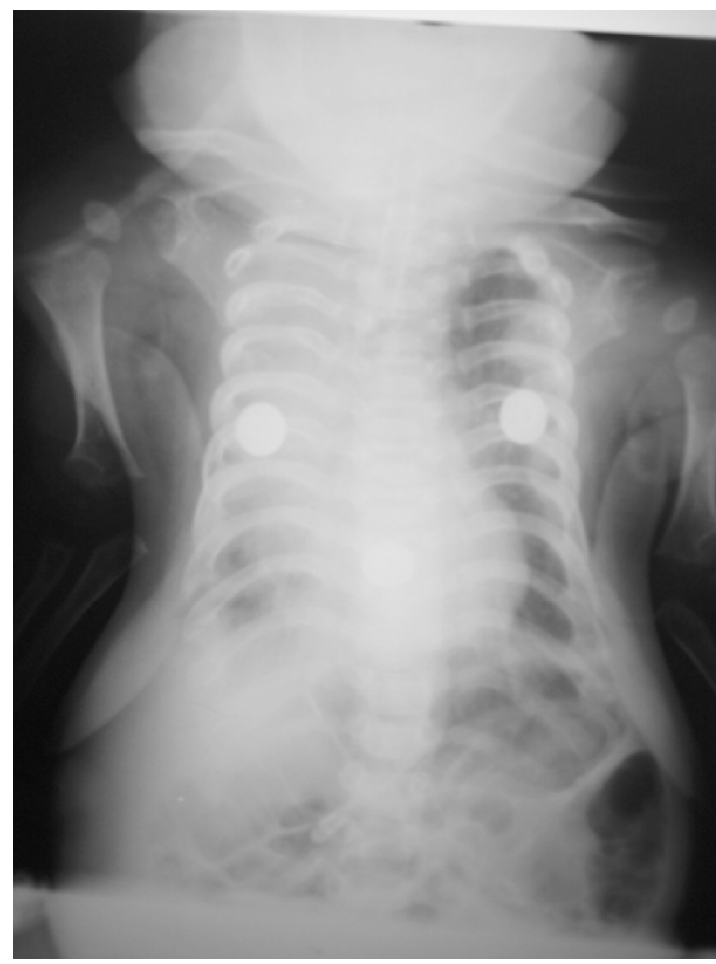

Figure 2 - Chest X-Ray: Reduced Thoracic Cage. 
surgical center, after anesthetic induction, central venous access puncture was conducted in right femoral vein and invasive blood pressure in left radial artery with Jelcoß 22. Anesthetic induction: Midazolam $0.7 \mathrm{mg}\left(0.1 \mathrm{mg} \cdot \mathrm{kg}^{-1}\right)$, sufentanyl $3.5 \mu \mathrm{g}\left(0.5 \mu \mathrm{g} \cdot \mathrm{kg}^{-1}\right)$, atracurium $3.5 \mathrm{mg}\left(0.5 \mathrm{mg}^{\mathrm{kg}}{ }^{-1}\right)$.

Maintenance: Sufentanyl continuous infusion $0.5 \mu \mathrm{g}$ to $1 \mu \mathrm{g} \cdot \mathrm{kg}^{-1} \cdot \mathrm{h}^{-1}$ and $2 \%$ sevoflurane. Hydration was conducted with 25 mL. kg-1 $0.9 \%$ sodium chloride +2 g 50\% glucose at first hour followed by hydration according to Holliday et al. ${ }^{11}$ method $\left(4 \mathrm{~mL} \cdot \mathrm{kg}^{-1} \cdot \mathrm{h}^{-1}\right)+$ surgery classification (8 mL. $\left.\mathrm{kg}^{-1} \cdot \mathrm{h}^{-1}\right)$.

Ventilation parameters: Pressure-cycled mechanical ventilation with inhalation pressure indexes of $31 \mathrm{~cm} \mathrm{H}_{2} \mathrm{O}$, respiratory frequency 30 incursions per minute, PEEP $12 \mathrm{~cm} \mathrm{H} \mathrm{H}_{2} \mathrm{O}, \mathrm{FiO}_{2} 80 \%$, expiratory volume around $50 \mathrm{~mL}$, inspiratory/expiratory time ratio $1: 1.5$ and minute volume 1.7. Initially, fraction of expired carbon dioxide was maintained at 40-50 $\mathrm{mm} \mathrm{Hg}$ and $\mathrm{O}_{2}$ saturation $96 \%-99 \%$. Thorax opening provided improved ventilation parameters, making it possible to reduce the inspiratory pressure with improvement of the expiratory volume. After placement of the thoracic prosthesis, however, limited ventilation was observed with increase in the inspiratory pressure being required. At this point, reduction in the expiratory volume and increase in the fraction of expired carbon dioxide were observed. Reduction of the thoracic prosthesis was performed with consequent ventilation improvement (inspiratory pressure $26 \mathrm{~cm} \mathrm{H} \mathrm{H}_{2} \mathrm{O}$, expiratory volume $62 \mathrm{~mL}$, PEEP $5 \mathrm{~cm} \mathrm{H} \mathrm{H}_{2} \mathrm{O}$, respiratory frequency 22 respiratory incursions per minute, fraction of expired carbon dioxide $42 \mathrm{~mm} \mathrm{Hg}$ ) (Table I). The procedure duration was 7 hours. Patient required blood replacement and received $100 \mathrm{~mL}$ packed red cells. Average blood pressure values were ranged from 50-60 mm Hg, blood glucose 79-154 mg.dL-1, hemoglobin 10.8-12.1 mg.dL-1.

Initial gasometry: $\mathrm{pH}$ 7.46, $\mathrm{PaCO}_{2} 32.8 \mathrm{~mm} \mathrm{Hg}, \mathrm{PaO}_{2}$ $168.2 \mathrm{~mm} \mathrm{Hg}, \mathrm{HCO}_{3} 23.3 \mathrm{mmol}^{-L^{-1}}$, BE $0.3 \mathrm{mmol} . \mathrm{L}^{-1}$ and $\mathrm{O}_{2}$ saturation $99.2 \%$.
Final gasometry: $\mathrm{pH}$ 7.447, $\mathrm{PaCO}_{2} 34.7 \mathrm{~mm} \mathrm{Hg}, \mathrm{PaO}_{2}$ $113.3 \mathrm{~mm} \mathrm{Hg}, \mathrm{HCO}_{3} 23.4 \mathrm{mmol} . \mathrm{L}^{-1}$, BE $0.0 \mathrm{mmol} . \mathrm{L}^{-1}, \mathrm{O}_{2}$ saturation $98,3 \%$. Diuresis was $0.53 \mathrm{~mL} \cdot \mathrm{kg}^{-1} \cdot \mathrm{h}^{-1}$.

At the end of the surgery epidurial blockade was applied. In left lateral decubitus position, the patient received thoracic antisepsis with alcoholic chlorhexidine, followed by Tuohy $20 \mathrm{G}$ needle puncture between T5 and T6. After the epidural space been located using the Dogliotti's technique of loss of resistance, morphine $200 \mu \mathrm{g}$ and fentanyl $15 \mu \mathrm{g}$ were administered. Patient was transferred to the neonatal ICU with orotracheal intubation and mechanical ventilation, maintaining previous ventilation parameters. Midazolam $2 \mathrm{mg}$ and atracurium $1 \mathrm{mg}$ intravenous in bolus infusion was administered for transportation.

\section{CONCLUSIONS}

Asphyxiating thoracic dystrophy is a rare recessive autosomal disease showing wide phenotype variability. Therefore, diagnosis of all present abnormalities is essential for the correct anesthetic management of the patient. In the pre anesthetic visit, pulmonary function is required to be assessed through the clinical condition, chest X-ray, computerized tomography, pulmonary function test and blood tests; in addition, check renal, hepatic and pancreatic functions.

During anesthesia, observation was necessary to adequate pre- and post-thoracotomy/thoracoplasty ventilation and to maintain patient hemodynamically stable. After thoracic opening, improvement in patient's ventilation parameters was observed. Reduction in the inspiratory pressure and improvement in the expiratory volume were made possible, with reduction of the fraction of expired carbon dioxide. However, after the thoracic prosthesis placement, the wide thoracic opening with the prosthesis was noted to restrict ventilation, returning to initial ventilation parameters (increase in the inspiratory pressure and reduction in the expiratory vol-

Table I - Ventilation Parameters

\begin{tabular}{|c|c|c|c|c|}
\hline Parameters & Initial & After thorax opening & $\begin{array}{l}\text { After prosthesis } \\
\text { placement }\end{array}$ & $\begin{array}{l}\text { After prosthesis } \\
\text { reduction }\end{array}$ \\
\hline Inspiratory pressure $\left(\mathrm{cm} \mathrm{H}_{2} \mathrm{O}\right)^{\star}$ & 31 & 28 & 32 & 26 \\
\hline Fraction of expired carbon dioxide $(\mathrm{mm} \mathrm{Hg})$ & $40-50$ & $35-45$ & $45-50$ & 42 \\
\hline Respiratory frequency (bpm) & 30 & 26 & 27 & 22 \\
\hline Inspiratory/expiratory time ratio & $1: 1.5$ & & & \\
\hline
\end{tabular}

* Pressured-cycled mechanical ventilation. 
ume). Therefore, prosthesis size readjustment and reduction of the thoracic opening were required to improve the ventilation parameters with reduction in the inspiratory pressure and increase in the expired volume. During surgery, a PEEP reduction was possible.

Ventilation control is one of the greatest intraoperative challenges. Patients with small thorax and short hypoplastic ribs experience great respiratory restriction with difficult pulmonary expansion. Thus, pressure-cycled mechanical ventilation is the most adequate type of ventilation to overcome the mechanical barrier. In the intraoperative setting, the ideal is to maintain the inspiratory pressure peak as low as possible to minimize the risk of barotraumas, venous return impairment, and reduced cardiac output. In addition, PEEP reduction is advisable to avoid its deleterious effects when reaching high values, such as the pulmonary air escape, reduced venous return, increased peripheral vascular resistance and carbon dioxide retention.

It is important to emphasize that postoperative analgesia is crucial for the patient to recover well. For this purpose, it was decided to have a thoracic analgesic blockade. Its benefits include: reduction in postoperative morbimortality and in atelectasis rate. In addition, an early patient extubation was intended in the Intensive Care Unit. 
9. Orfaliais CS, March MFP, Ferreira $S$ et al. - Distrofia torácica asfixiante de Jeune: relato de 3 casos. Jornal de Pediatria, 1998;74:333337.

10. Molinero LR, Mena EJ, Tudelilla JMM et al. - Distrofia torácica asfixiante o enfermedad de Jeune. Bol Pediatr, 1990;31:135-139.

11. Holliday MA, Segar, WE - The maintenance need for water in parenteral fluid therapy. Pediatrics, 1957;19(5):823-32.

\section{REFERÊNCIAS/REFERENCES}

1. Chen $\mathrm{H}-$ Asphyxiating thoracic dystrophy (Jeune Syndrome). eMedicine, 2009.

2. Morgan NV, Bacchelli C, Gissen $C$ et al. - A lócus for asphyxiating thoracic dystrophy, ATD, maps to chromosome 15q13. J Med Genet, 2003;40:431-435.

3. Sahin N, Kara H, Ertugrul $\mathrm{F}$ et al. - Jeune Sendromu ve Anestezi. Turkiye Klinikleri J Anest Reanim, 2007;5:150-153.

4. Borland LM - Anesthesia for chilren with Jeune's Syndrome (asphyxiating thoracic dystrophy). Anesthesiology, 1987;66:86-88.

5. Schinzel A, Savoldelli G, Briner J et al. - Prenatal sonographic diagnosis of Jeune Syndrome. Radiology, 1985:154:777-778.

6. Davis JT, Ruberg RL, Leppink DM et al. - Lateral thoracic expansion for Jeune's asphyxiatin dystrophy: a new approach. Ann Thorac Surg, 1995;60:694-696.

7. Davis JT, Heistein JB, Castile RG et al. - Lateral thoracic expansion for Jeune's syndrome: midterm results. Ann Thorac Surg, 2001;72:872877.

8. Baum VC, OF'laherty JE - Anesthesia for genetic, metabolic and dysmorphic sydromes of childhook, $2^{\text {ed }}$, Philadelphia: Lippincott Williams \& Wilkins; 2007;191-192. 